\title{
Spatial and Temporal Scales in Altimetric Variability in the Brazil-Malvinas Current Confluence Region: Dominance of the Semiannual Period and Large Spatial Scales
}

\author{
Christine Provost
}

Laboratoire d'Océanographie Dynamique et de Climatologie, Centre National de Recherche Scientifique, Université de Paris VI

\author{
Pierre-Yves Le Traon
}

Collecte Localisation Satellites Argos, Toulouse, France

\begin{abstract}
Two years of Geosat data are used to investigate the space and time scales of the mesoscale variability in the Brazil-Malvinas Current confluence region. The mesoscale activity is highly inhomogeneous and anisotropic. The inhomogeneity is characterized by low values of sea level variability in the Malvinas Current (less than $8 \mathrm{~cm}$, i.e., eddy kinetic energy less than $150 \mathrm{~cm}^{2} \mathrm{~s}^{-2}$ ), intermediate values in the Brazil Current (typically $16 \mathrm{~cm} / 800 \mathrm{~cm}^{2} \mathrm{~s}^{-2}$ ) and high values in the Brazil-Malvinas frontal region $\left(30 \mathrm{~cm} / 1700 \mathrm{~cm}^{2} \mathrm{~s}^{-2}\right)$. The anisotropy is marked with meridional variances of velocity that are typically three times larger than zonal ones in the region of maximum variability. Mesoscale variations are dominated by relatively large spatial scales and low-frequency fluctuations. Contrary to similar spectra derived from Geosat data over the North Atlantic (Le Traon, 1991; Le Traon et al., 1990) or over the whole southern ocean (Chelton et al., 1990) there is very little energy at the annual period. In the mean spectrum, the energy is at least 3 times smaller at the annual period than at the semiannual period or at shorter periods. The semiannual signal, with length scales of about $400-500 \mathrm{~km}$, has a clear northward propagation and is maximum in the frontal region. It is probably associated with the semiannual wave that dominates the atmospheric circulation in the southern hemisphere. However, the mechanism responsible for this semiannual signal in the frontal region remains unclear. Beyond this dominant semiannual frequency, the altimetry-derived mesoscale fluctuations exhibit other energetic signals, especially signals at periods between 75 and 150 days and spatial scales of $500-600 \mathrm{~km}$ with a westward propagation which have characteristics consistent with the dynamics of barotropic Rossby waves.
\end{abstract}

\section{INTRODUCTION}

The Brazil-Malvinas confluence area $\left(34^{\circ}-46^{\circ} \mathrm{S}, 43^{\circ}-60^{\circ} \mathrm{W}\right)$ is a highly dynamic region of the western boundary of the South Atlantic. A schematic representation of the geostrophic time averaged mass transport of the upper $1000 \mathrm{~m}$ based on the hydrographic data collected within the Confluence Program is shown in Figure 1 [Confluence Principal Investigators, 1990]. Two major currents with strongly contrasting water types, the Brazil and Malvinas (Falkland) currents, meet in this zone, generating a strong frontal structure and a complex array of eddies, rings and filaments [Gordon, 1989]. The contrasts in sea surface temperature (SST) and the local maximum in eddy kinetic energy make satellite infrared (IR) imagery [Legeckis and Gordon, 1982] and satellite altimetry [Provost et al., 1989] particularly appropriate tools to study the confluence region. The satellite data provide valuable surface information in this remote area, which, like most of the southern hemisphere oceans, has few in situ time series observations.

Most of our present knowledge of the variability in the confluence region comes from previous studies using satellite IR images which reveal several time and space scales of SST variability. Analyses of 3 years (July 1984 to June 1987) of satellite IR images have shown the dominance of an annual cycle [Podesta et al., 1991] and the existence of a

Copyright 1993 by the American Geophysical Union.

Paper number 93JC00693

0148-0227/93/93JC-00693\$05.00 semiannual signal [Provost et al., 1992] in the SST time variations.

The location at which the Brazil Current separates from the coast appears to have annual and semiannual variations and seems to be situated further north during winter than during summer [Olson et al., 1988]. The associated fluctuations of the western boundary of the warm water (Brazil Current) have meridional length scales of the order of 1000 $\mathrm{km}$ and zonal scales of $50 \mathrm{~km}$ [Legeckis and Gordon, 1982].

After separating from the western boundary, the Brazil Current joins with the return flow of the Malvinas Current and continues to flow in a general southward direction for some distance. The southern limit to the warm water bounded by the Brazil Current has been observed to fluctuate between $38^{\circ}$ and $46^{\circ} \mathrm{S}$ and $50^{\circ}$ and $55^{\circ} \mathrm{W}$, a distance of nearly $900 \mathrm{~km}$, over time scales of about 2 months [Legeckis and Gordon, 1982]. The southward extensions of the Brazil Current are followed by the shedding of warm-core eddies which are lost to the Subantarctic zone of the Antarctic Circumpolar Current. Those eddies formed during the northward retreat of the Brazil Current are numerous and have a diameter of about $150 \mathrm{~km}$ [Olson et al., 1988; Gordon, 1989].

After reaching a southern limit, the Brazil Current reverses direction and flows equatorward just east of its poleward flow. The western and eastern SST boundaries of the warm water overshoot are separated by 150 to $300 \mathrm{~km}$ [Legeckis and Gordon, 1982].

Concurrently with the large-scale meridional frontal displacements, time-dependent wavelike disturbances with 


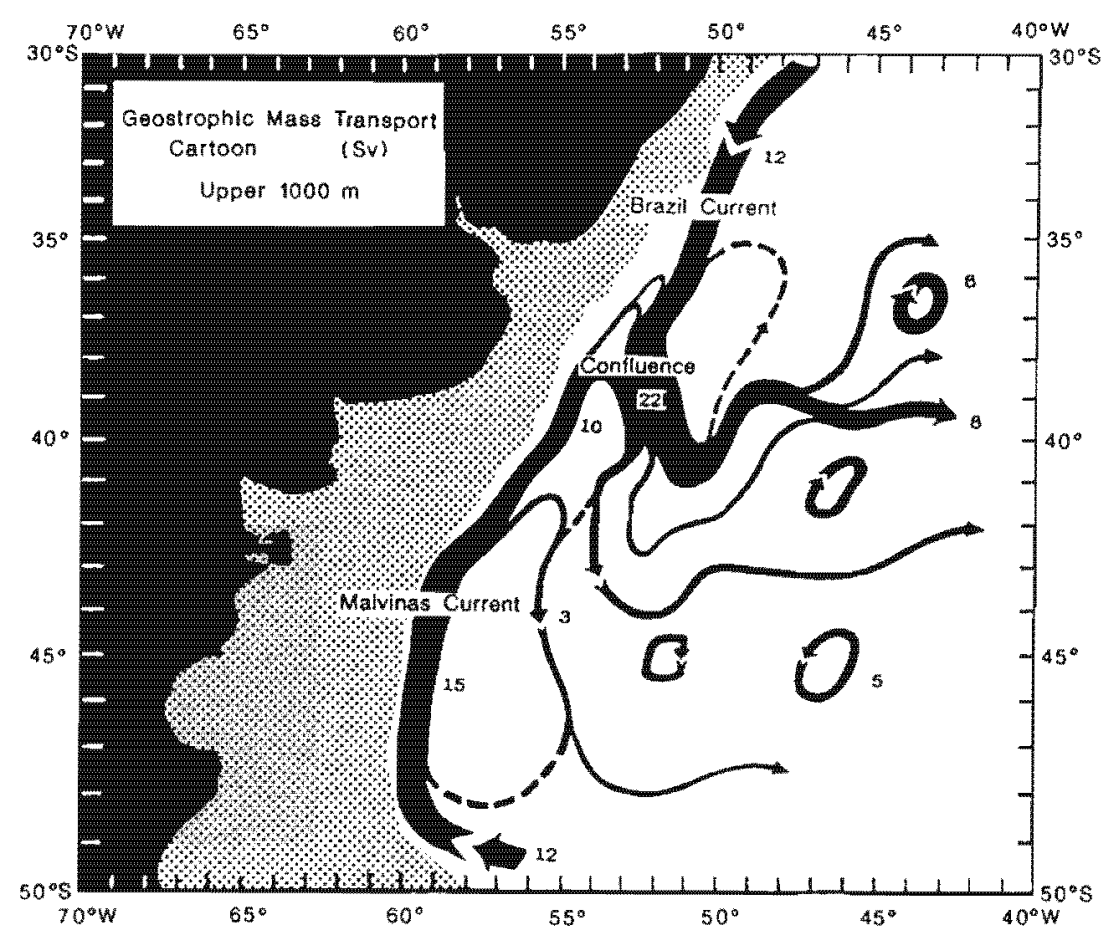

Fig. 1. Schematic of geostrophic time averaged mass transport in the upper $1000 \mathrm{~m}$ in the western Argentine Basin based on the hydrographic data collected during the Confuence Program. The transports given are in sverdrups (1 Sv $=10^{6} \mathrm{~m}^{3} \mathrm{~s}^{-1}$ ) (Redrawn from Confuence Principal Investigators [1990, Figure 1].

shorter length scales occur intermittently. Significant dis. placements of the western SST boundary associated with the Brazil Current can occur on time scales of about 1 week or longer, with along-stream spatial scales of $200 \mathrm{~km}$ [Legeckis and Gordon, 1982].

However the valuable information provided by satellite $I R$ images should always be examined carefully. Superficial ocean processes like the establishment of a shallow seasonal thermocline might hide the "real" deeper boundary between the Malvinas and Brazil currents characterized by the strong deeper front [Legeckis and Gordon, 1982; Olson et al., 19881.

This paper aims at describing the space and time scales of variability of the confluence region using another type of satellite data, altimetric data. Altimeter-derived sea level variations do not merely represent surface ocean phenomena but rather show the dynamics of the whole water column. Data from altimetry produce a space-time coverage of the ocean that makes determination of mesoscale the spectral characteristics possible. For example, mesoscale space and time statistics in the North Atlantic have been derived in a systematic manner from Geosat data [Le Traon et al., 1990; Le Traon, 1991], and their significant differences in latitude and longitude have been related to different types of forcing and dissipation mechanisms.

The statistics of the whole southern ocean variability have been examined through satellite altimetric data [e.g., Cheney et al, 1983; Daniault and Ménard, 1985; Chelton et al., 1990]. Chelton et al. [1990], analyzing 26 months of Geosat data, show that the strongest velocity variability in the first empirical orthogonal function (EOF) (which represents mainly the annually forced variability) occurs near the subtropical front in each ocean basin. Otherwise, they find that mesoscale variability is strongest near the axis of the
Antarctic Circumpolar Current and suggest that it is related to instabilities of the mean current. In their large-scale EOF analysis, 20 modes are needed to explain $80 \%$ of the variance. In each of the EOFs presented, the confluence region appears as an extremum. They interpret the "white" character of the EOF spectrum as an indication that the coherence of the sea level variability in the southern ocean is fundamentally regional rather than zonal, even on the large space and time scales resolved by the smoothed data.

In this paper the local sea level variability in the confluence region is examined from a statistical point of view using 2 years of Geosat data. The method used for computing sea level residuals is described briefly. We discuss the issues of inhomogeneity and anisotropy in section 2 . The analyses developed in section 3 lead to a spectral characterization of the mesoscale fluctuations, and we address the issue of seasonal variability of the statistical and spectral characteristics. The interpretation of the results follows in section 4 in relation to the characteristics of the atmospheric circulation. Section 5 summarizes the major results and provides the main conclusions.

\section{INHOMOGENEITY AND ANISOTROPY}

We briefy outline the data processing, which is standard except for the orbit error removal (detailed in the appendix). Altimetric sea surface height and geostrophic current variabilities can provide useful information on inhomogeneity and on spatial scales of variability. Anisotropy is then examined through the calculation of the main axes of variance of velocity fuctuations.

\subsection{Altimeter Data Processing}

We used 2 years of Geosat geophysical data records (GDRs) obtained from the National Oceanic and Atmo- 


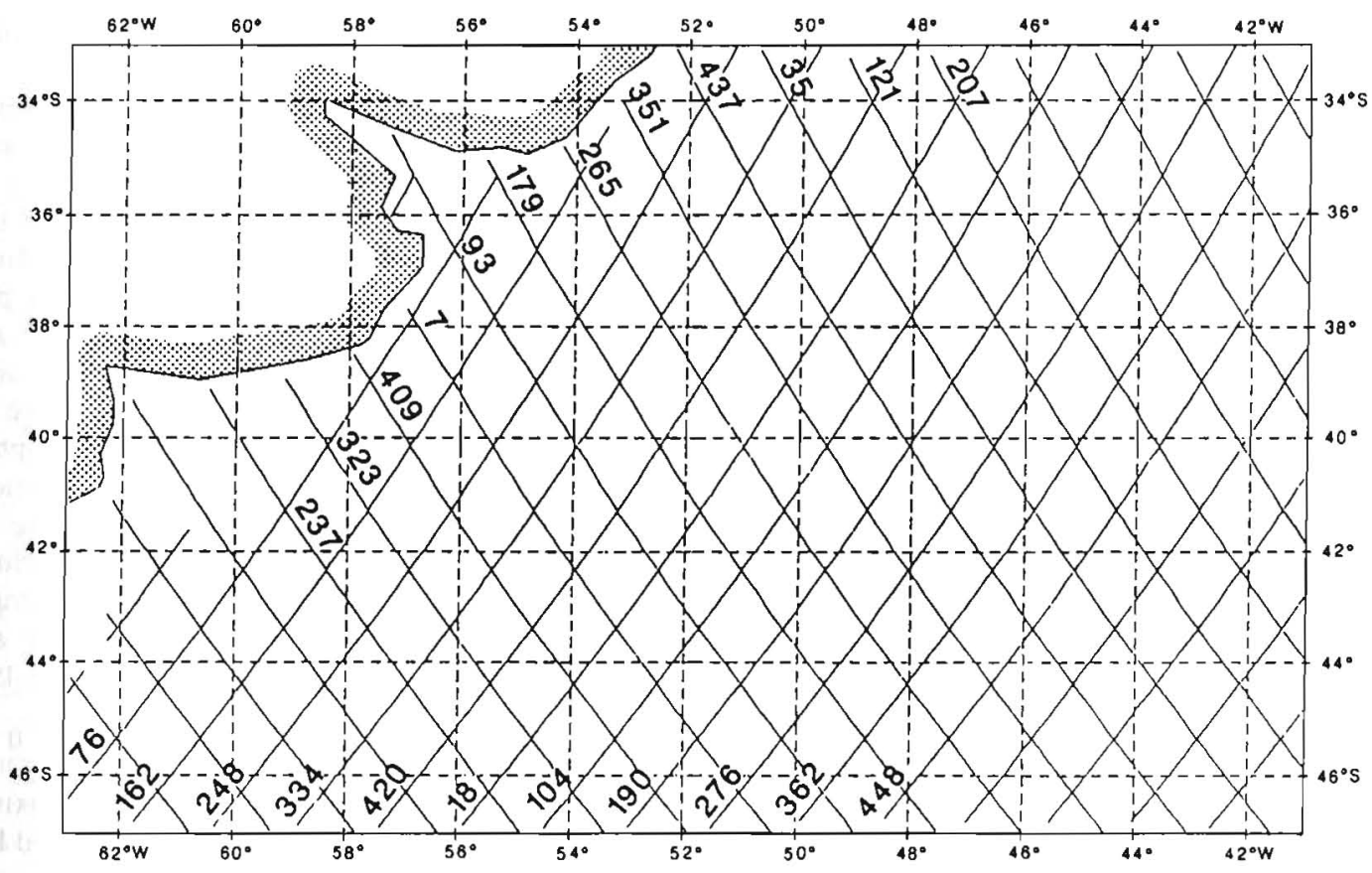

Fig. 2. The study area in the South Atlantic $\left(-45^{\circ}--35^{\circ} \mathrm{S},-65^{\circ}--45^{\circ} \mathrm{W}\right)$; the Geosat tracks are superimposed. The 23 tracks used in the analyses are labeled.

spheric Administration (NOAA) spanning the period from November 1986 to December 1988, i.e., 44 cycles of 17.05 days. The Geosat tracks over this region are shown in Figure 2. The average zonal distance between two adjacent tracks is about 1.4 degree of longitude. The distance between two data points on a track is $6.8 \mathrm{~km}$. The procedures applied to process these data are described in detail by Le Traon et al. [1990] and will be recalled only briefly here.

The sea surface height (SSH) measurements were first corrected for the following effects (corrections available in the GDRs): electromagnetic bias by adding $2 \%$ of significant wave height $\left(H_{1 / 3}\right)$ to the SSH, ocean tides using the Schwiderski model, terrestrial tides using the Melchior model, ionospheric effects using the Global Positioning System climatic model, and dry and wet tropospheric effects using Fleet Numerical Oceanography Center data [Cheney et al., 1987]. Because of the uncertainties in estimating an inverted barometer correction [Zlotnicki et al., 1989], none was applied. The SSH profiles were then resampled regularly every $10 \mathrm{~km}$ using a cubic spline (the initial sampling rate is $6.8 \mathrm{~km}$ ) and the mean profile was subtracted from each individual profile.

A polynomial adjustment with weights inversely proportional to the mesoscale variance, thus taking into account the inhomogeneity of the mesoscale field (see appendix), was used to remove orbit error [Le Traon et al., 1991]. This gives the mesoscale sea level anomaly (SLA) sampled every 10 $\mathrm{km}$, at the time of the satellite pass on the given track. A Lanczos filter with a cutoff wavelength of $100 \mathrm{~km}$ was then applied to the SLA data to filter out instrumental noise. Geostrophic velocities were then obtained by centered finite differences.

\subsection{Variability of Sea Level Anomaly and Surface Geostrophic Velocity Anomaly}

Maps of sea level anomaly variability have been obtained according to the method described by Le Traon et al. [1990].
The study area is divided into $2^{\circ}$ latitude by $2^{\circ}$ longitude bins. Mean variances and associated errors are computed over each bin. Errors are assumed to have a Gaussian distribution, a decorrelation time of 34 days, and a spatial decorrelation scale of $100 \mathrm{~km}$. These decorrelation scales correspond roughly to the first zero crossing of spatial and temporal autocorrelation functions (see section 3). An objective analysis is then performed using Gaussian correlation functions with standard deviations of $2^{\circ}$ in latitude and $2^{\circ}$ in longitude. The associated error is generally of the order of $5 \%$ at 1 standard deviation.

The region is very inhomogeneous: variabilities in SLA vary between 6 and $30 \mathrm{~cm}$ (Figure $3 a$ ). The maximum values are located from $39^{\circ} \mathrm{S}$ to $42^{\circ} \mathrm{S}$ in latitude and $54^{\circ} \mathrm{W}$ to $48^{\circ} \mathrm{W}$ in longitude and correspond to the frontal region separating the warm and salty Brazil Current to the north from the cold and fresher Malvinas Current to the southwest [Legeckis and Gordon, 1982]. The maximum variability does not occur at the separation of the currents from the coast but rather is slightly offshore, over the $5000-\mathrm{m}$ bathymetric isoline, i.e., on the offshore side of the continental slope. The variability also diminishes further offshore. Variability is smaller in the Brazil Current ( 16 to $12 \mathrm{~cm}$ ) and even smaller in the Malvinas Current (below $8 \mathrm{~cm}$ ). Eddies have been observed in the Brazil Current both by satellite data [Legeckis and Gordon, 1982] and with in situ observations [Evans and Signorini, 1985].

We have computed the corresponding surface geostrophic velocity anomalies (SGVA) assuming isotropic variability. The map of the SGVA variance (Figure $3 b$ ) shows values varying from 100 to $1700 \mathrm{~cm}^{2} \mathrm{~s}^{-2}$. As is the case for the SLA, the maximum of variability is located between $39^{\circ} \mathrm{S}$ and $42^{\circ} \mathrm{S}$ and between $54^{\circ} \mathrm{W}$ and $48^{\circ} \mathrm{W}$ and is associated with the frontal region. However, in a frontal region such as the Brazil-Malvinas confluence, geostrophy may not be an accurate approximation. The geostrophic variability obtained from altimetry compares well regarding both structures and 

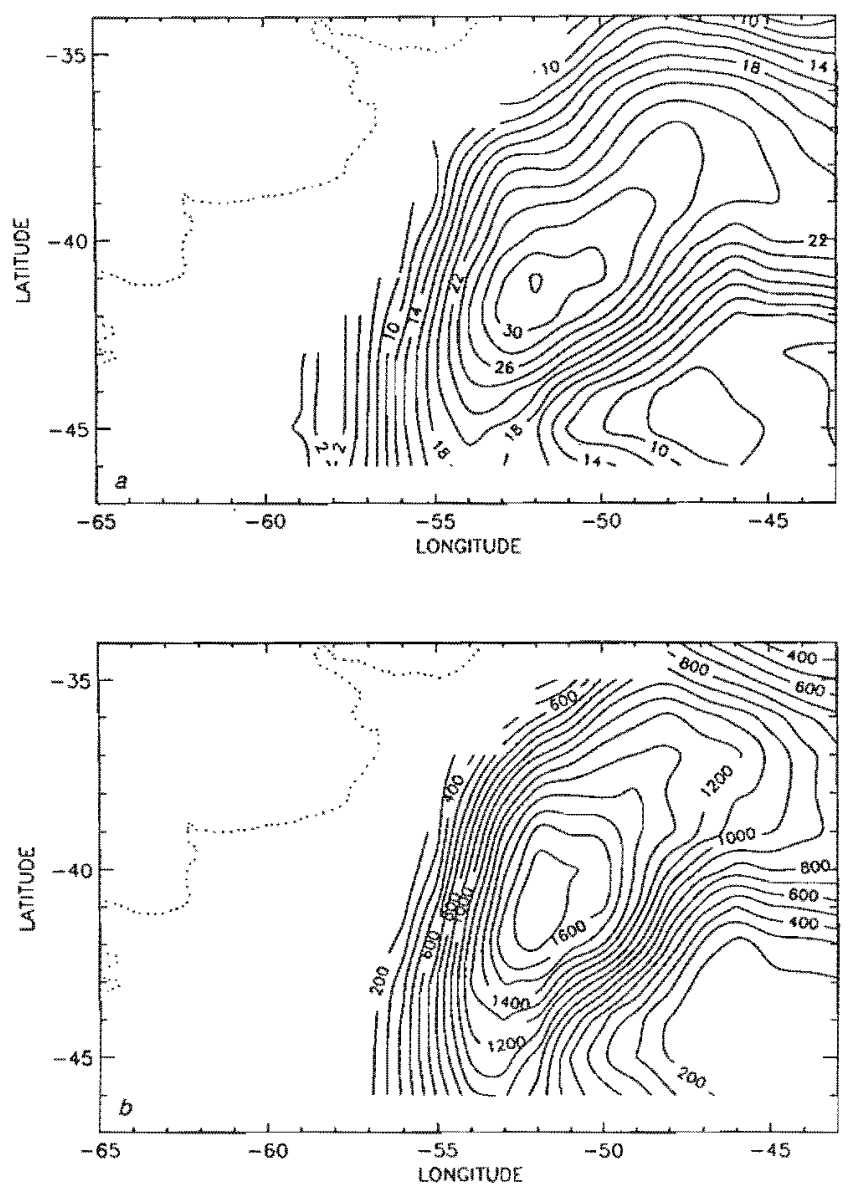

Fig. 3, (a) Root square variability of sea level anomaly after weighted polynomial adjustment (2-cm isolines). (b) Variance of the surface geostrophic velocity anomaly $\left(100 \mathrm{~cm}^{2} \mathrm{~s}^{-2}\right.$ isolines).

absolute values with the eddy kinetic energy (EKE) calculated from the drifting buoys of the First GARP Global Experiment [Patterson, 1985; Piola et al., 1987; Large and Van Loon, 1989; Johnson, 1989].

The $2^{\circ} \times 2^{\circ}$ averaging and the objective analysis have reduced the observed maximum values. The variability obtained directly on the tracks can reach $40 \mathrm{~cm}$ for the SLA and $2500 \mathrm{~cm}^{2} \mathrm{~s}^{-2}$ for the EKE. However the statistical error on these point estimations along the tracks is high (above $15 \%$ and $30 \%$ at 1 standard deviation for SLA and EKE respectively).

\subsection{Anisotropy}

The maps discussed above are obtained under the assumption that variances along the ascending and descending tracks are similar. A first way to characterize anisotropy is, for example, to calculate the variance of SGVA using only ascending arcs (not shown) and only descending arcs (not shown). The statistical error on these maps is typically greater than the error associated with Figures $3 a$ and $3 b$ by a factor of $2^{1 / 2}$, and the differences between these maps are probably not statistically significant. Therefore the hypothesis of isotropy along those two directions happens to be rather well verified in the confluence region. This does not mean, however, that mesoscale fluctuations are isotropic: for example, a zonal or meridional anisotropy would not show up here because of the particular orientation of ascending and descending arcs.

To quantify anisotropy, we compute the principal axes of variance of velocity fuctuations. To do so, we need to estimate the time-averaged components of the horizontal velocity correlation matrix. We first calculate the components of the geostrophic velocity perpendicular to each track (ascending and descending) at each crossover point. They are then interpolated linearly to common time, and used to derive the zonal and meridional components $u^{\prime}$ and $v^{\prime}$ of the geostrophic velocity fluctuations. Because of the orientation of the satellite tracks, the error on the geostrophic velocity estimates is anisotropic: the error on the meridional geostrophic velocity is about twice as large as the one on the zonal velocity estimates. The covariances of velocity fluctuations, $\left\langle u^{\prime 2}\right\rangle,\left\langle v^{\prime 2}\right\rangle$, and $\left\langle u^{\prime} v^{\prime}\right\rangle$, are then computed. The principal axes of variance may be found by solving the following eigenvalue problem [Freeland et al., 1975]:

$$
\left(\left\langle u^{2}\right\rangle-\lambda\right)\left(\left\langle v^{\prime 2}\right\rangle-\lambda\right)-\left\langle u^{\prime} v^{\prime}\right\rangle^{2}=0
$$

The angle $\theta$, the orientation of the principal axis measured counterclockwise from latitude lines, is defined by

$$
\tan 2 \theta=2\left\langle u^{\prime} v^{\prime}\right\rangle /\left\langle u^{\prime 2}-v^{\prime 2}\right\rangle
$$

The principal axes of variance (Figure $4 a$ ) show that the region is strongly anisotropic with meridional variances of velocity that are typically 3 times more important than zonal variances in the region of maximum variability. Along the continental slope, velocity fluctuations have a preferential direction parallel to the slope. As the principal axes have preferentially a meridional direction, the anisotropy tends to disappear when projected on to the ascending and descending arcs, and this is why variability maps obtained using only ascending arcs are similar to those obtained using only descending arcs. The main discrepancies between those maps are indeed located in the regions where the principal axes do not have a meridional direction.

The anisotropy ratio (greatest variance/smallest variance; not shown) varies from 2 to 8 over the region. This ratio obeys Fisher's law, and according to our decorrelation hypothesis ( 34 days, i.e., 1 cycle over 2 ), values greater than 2.5 are statistically significant. This anisotropy is maximum in the frontal region, i.e., in the most energetic region.

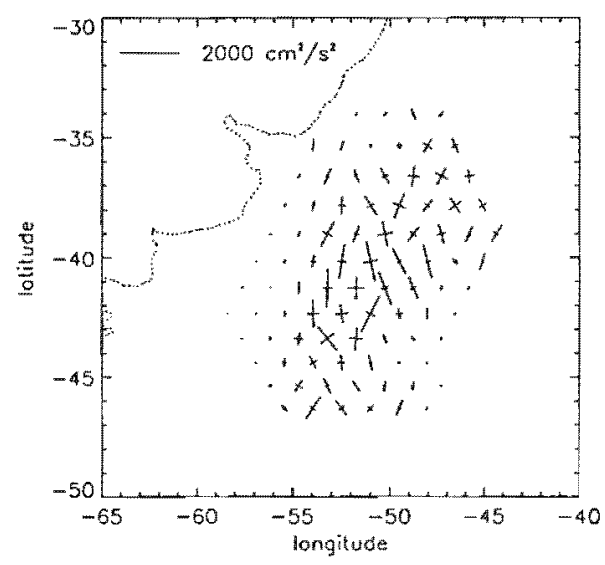

Fig. 4a. Principal axes of the variance of geostrophic velocity at crossover points. Meridional variances are typically 3 times larger than zonal variances. 
The spatial distribution of time-averaged Reynolds stresses $\left\langle u^{\prime} v^{\prime}\right\rangle$ is shown in Figure $4 b$ and should be compared with the schematic mean flow of Figure 1. In the time-averaged sense, the "eddy" of negative Reynolds stresses centered at $40^{\circ} \mathrm{S}, 50^{\circ} \mathrm{W}$, slows down the cyclonic flow of the Brazil Current overshoot, whereas the negative Reynolds stresses to the south accelerate the anticyclonic flow of the Malvinas Current and hence the return flow.

\section{Spectral Characteristics}

\subsection{Spatial and Temporal Autocorrelations}

The spatial autocorrelation function $c(r)$ of the SLA calculated from all the tracks over the region using the method described by Le Traon et al. [1990] has a first zero crossing at $160 \mathrm{~km}$. This value depends strongly upon the polynomial adjustment (see appendix). The spatial autocorrelation function for the geostrophic velocity (or crosscorrelation function of the velocities $g(r)=-c^{\prime \prime}(r)$ ), although more difficult to estimate, gives a more significative estimation of spatial scales. Polynomial adjustment effects are then negligible. The first zero crossing of $g$ is about 75 $\mathrm{km}$, to be compared with the $55 \mathrm{~km}$ found in the Gulf Stream [Le Traon et al., 1990]. This scale is much greater than the first internal Rossby radius, which is about $27 \mathrm{~km}$ in the region [Houry et al., 1987].

The mean temporal autocorrelation function has its first zero crossing at 68 days. To examine the time scales and their spatial variation in greater detail, we calculate the 17-day isocorrelations $C(17) / C(0)$ in $2^{\circ}$ latitude by $2^{\circ}$ longitude bins. The 17-day isocorrelation map of SLA (Figure 5) is obtained with the objective analysis described above [Le Traon, 1991]. The formal error on these estimates (assuming a spatial decorrelation of $100 \mathrm{~km}$ ) is of the order of $5 \%$, which shows that observed variations are significant. The 17-day isocorrelations show values between $10 \%$ and $50 \%$.

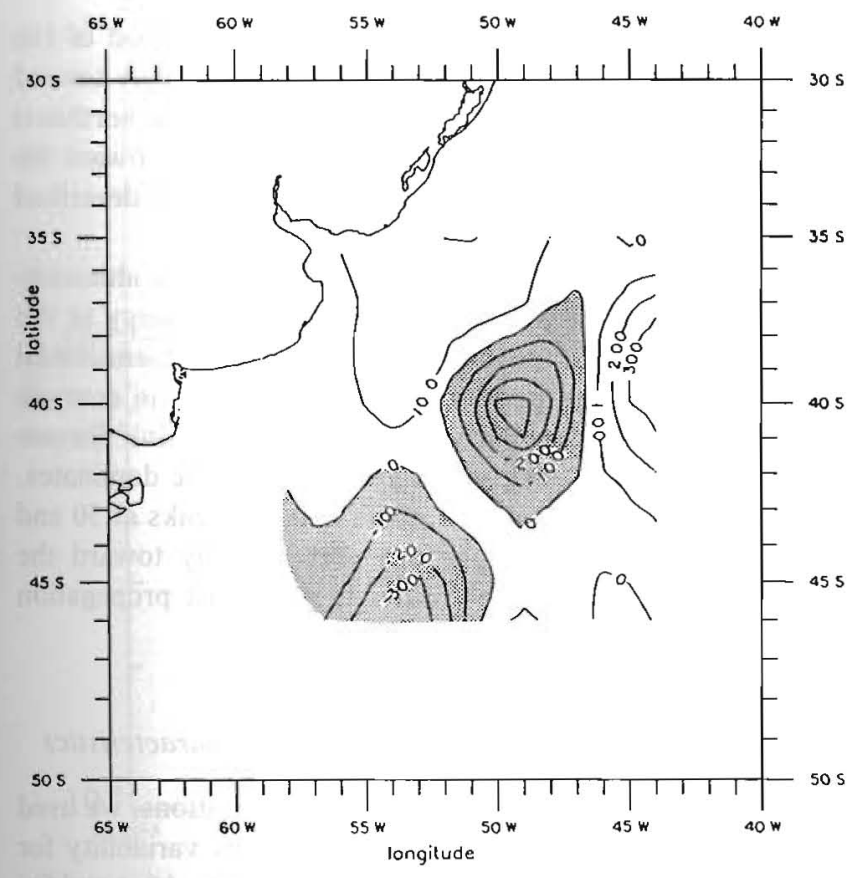

Fig. 4b. Spatial distribution of time-averaged Reynolds stresses. Areas of negative averaged Reynolds stresses are shaded.

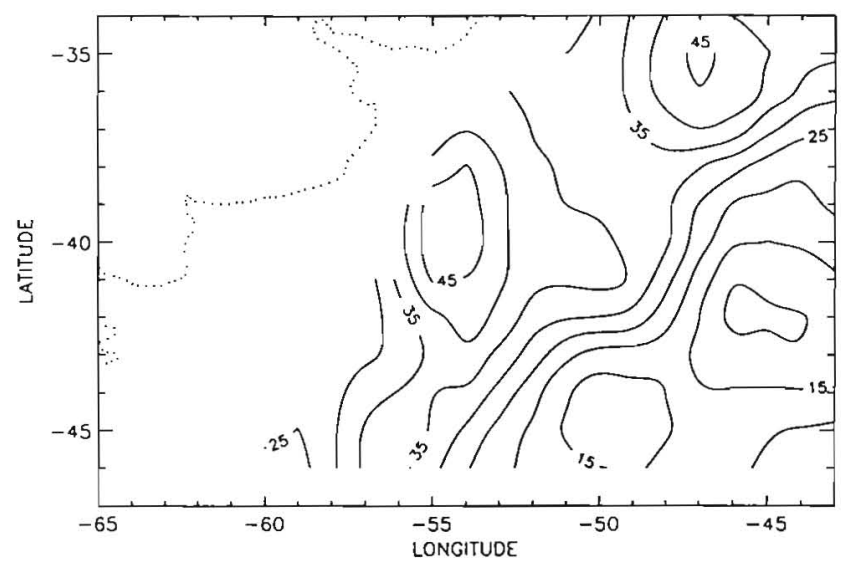

Fig. 5. The 17-day isocorrelations of sea surface topography (in percent). The $25 \%$ isoline is parallel to the bathymetry and corresponds to ocean depth of $5500 \mathrm{~m}$. It separates highly correlated regions over the continental slope from poorly correlated regions in the deep ocean.

The most energetic region has 17-day isocorrelation greater than $30 \%$. The least energetic region in the southeast has the lowest correlation. In contrast, similar calculations over the Gulf Stream show that areas of weak temporal correlation correspond to areas of high mesoscale activity [Le Traon, 1991]. The $25 \%$ and $30 \%$ isolines are parallel to the bathymetry, corresponding to an ocean depth of $5500 \mathrm{~m}$, and separate highly correlated regions over the continental slope from poorly correlated regions in the deep ocean. Over the slope, in the region of maximum variability, velocity fluctuations have a preferential direction parallel to the coast and have high temporal correlations.

\subsection{Wavenumber Spectra}

The mean wavenumber spectrum over the region (Figure 6) has been computed over all tracks of length greater than $1000 \mathrm{~km}$, i.e., over 22 tracks. A total of 778 profiles have been selected. In the calculation, the mean and the slope have been taken out of the residuals in order to avoid spectral leakage [Le Traon et al., 1991]. The confidence interval assumes a spatial decorrelation of $300 \mathrm{~km}$ and a temporal decorrelation of 34 days (one track out of three being independent, one cycle out of three being uncorrelated). It is therefore rather pessimistic. The observed noise level is about $200 \mathrm{~cm}^{2} / \mathrm{cycle} / \mathrm{km}$ which corresponds to about $3.5 \mathrm{~cm}$ rms for scales less than $45 \mathrm{~km}$.

The spectral slope between 100 and $350 \mathrm{~km}$ is about -4 , a typical value for the steep slopes characterizing energetic regions [Le Traon et al., 1990]. We observe a first break in the slope between 300 and $400 \mathrm{~km}$, and the spectrum remains red afterward. This redness corresponds to the large spatial scales observed. For scales larger than $600 \mathrm{~km}$, the spectrum is much flatter. The lower level for scales larger than 1000 $\mathrm{km}$ is not significant owing to the influence of the polynomial adjustment. The mean spectra for ascending and descending tracks have been computed and do not present any significant differences.

\subsection{Frequency Spectra}

Frequency spectra have been calculated over $2^{\circ}$ latitude by $2^{\circ}$ longitude bins as was described by Le Traon [1991]. 


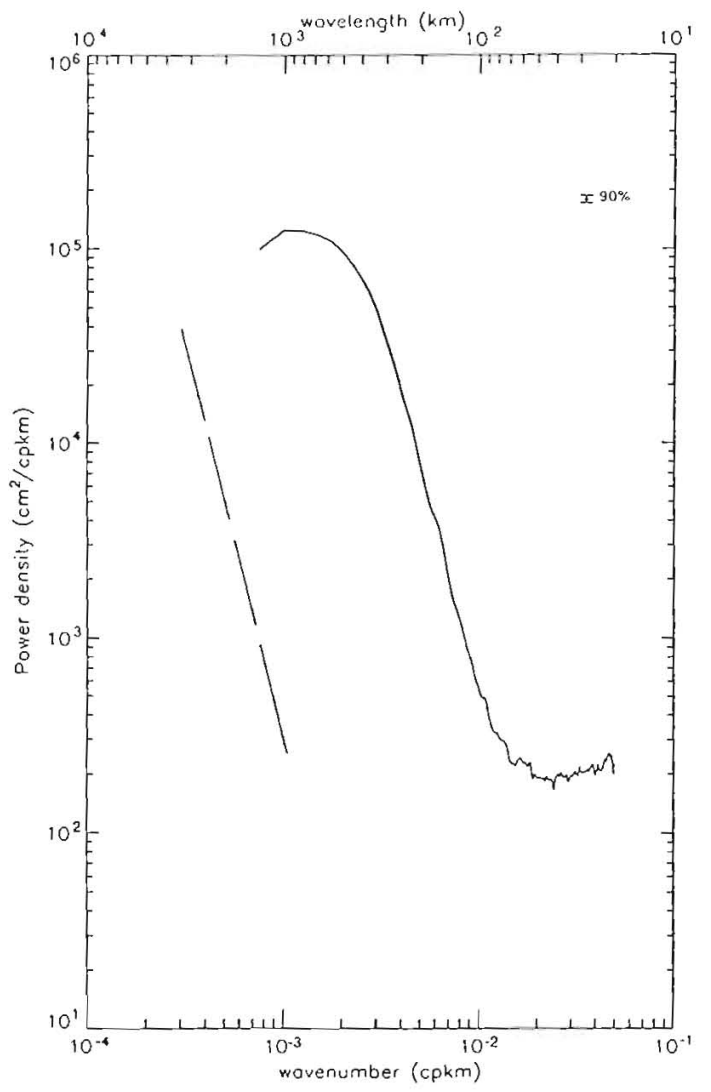

short place 1 Brazi] longe) and $C$

deepe. 1988].

but ra

Data $f$

ocean

charac

time $s$

systen

Le Tre

and $l o$ : and di.

The

been e et al., 1990].

data, s empiri mainly subtro that $\mathrm{m}$
Fig. 6. Mean wavenumber spectrum over the confluence region. The spectral slope between 100 and $300 \mathrm{~km}$ is about -4 . A straight line with a -4 slope is drawn.

Figure 7 shows these spectra as a function of location in space. They are not in variance-preserving form and therefore increase the relative importance of large periods. Each spectrum is calculated with a relatively small number of data, and the $90 \%$ statistical confidence level is represented for each spectrum. Although noisy, all the spectra show a remarkably high level of energy at the semiannual period.

The spectra of the three boxes located over the continental platform (1, 2, and 3) show peaks at the annual period. These spectra are probably aliased because of poor tidal corrections over shallow water. The spectra corresponding to the frontal region $(4,5,7,8$, and 9 ) are dominated by a peak at the semiannual period, whereas the spectra corresponding to the eastern part of the region $(10,11,13$, and 14) are dominated by smaller periods. In most spectra (e.g., 11) the interannual period is energetic.

\subsection{Frequency-Wavenumber Spectra of SLA}

Frequency-wavenumber spectra have been computed as described by Le Traon [1991]. Figure 8 shows the mean total spectrum. The mean progressive spectra (propagation in the direction of increasing latitudes) and retrogressive spectra (propagation in the direction of decreasing latitudes) are shown for all descending tracks in Figures $9 a$ and $9 b$, respectively, and for all ascending tracks in Figures $9 c$ and $9 d$, respectively. These spectra are in variance-preserving form. Three ascending tracks (tracks 237, 323, and 437; see Figure 2) have not been considered in the computation because they are incomplete. A total of 20 track been selected ( 11 ascending and 9 descending) whi suming the independency of each other 3 tracks, give 30 degrees of freedom in the spectral estimates statistical accuracy on the spectra of $30 \%$ at th confidence limit).

The mean total spectrum (Figure 8 ) exhibits a con band with energies higher than $150 \mathrm{~cm}^{2}$; this band is by spatial scales of 300 and $800 \mathrm{~km}$ and by time scale and 250 days. Within this energetic region, three $t$ significant peaks are easily identified.

First, some energy is observed at periods less than which probably includes some aliasing. The Nyqu quency of 34 days $^{-1}$, which is the upper limit for freq observable by Geosat, definitely places a limit on the vation of certain mesoscale structures in the con region. The high propagation speeds $\left(>20 \mathrm{~km} \mathrm{~d}^{-1}\right) 0$ and warm rings observed in satellite IR imagery [ $L$ and Gordon, 1982] certainly create some aliasing shorter periods onto longer periods. Two peaks at 50 days (values higher than $150 \mathrm{~cm}^{2}$ ) are observed northeast propagation spectrum (Figure $9 a$ ) at a wav of $350 \mathrm{~km}$. They correspond to phase speeds of 7.4 $\mathrm{cm} \mathrm{s} \mathrm{s}^{-1}$, respectively, and to a propagation of $\mathrm{d}$ parallel to the continental slope.

Second, a large amount of energy $\left(>250 \mathrm{~cm}^{2}\right)$ is ob at periods between 75 and 150 days and wavelen about $500 \mathrm{~km}$ which tends to propagate westward: th maximum of energy is seen only on the spectra of $p$ tion toward the southwest and northwest (Figures $9 \mathrm{c}$ ). The associated phase speeds of propagation va 6 to $4 \mathrm{~cm} \mathrm{~s}^{-1}$. The 80-day peak appears mostly propagation of direction southwest at a wavelength $\mathrm{km}$. The 130-day peak appears for propagation bot southwest direction at a wavelength of $600 \mathrm{~km}$ an northwest direction at a somewhat shorter wave le about $450 \mathrm{~km}$.

Third, there is a high peak at $500 \mathrm{~km}$ at a perio days. This semiannual signal propagates essentially the north, with an important propagation to the $\mathrm{n}$ (Figure $9 a$ ) and a somewhat smaller propagation tor northwest (Figure 9c). This semiannual signal is $d$ and discussed further in section 4.

There is no clear peak at the annual cycle in the a derived spectra. In the mean spectrum, the energ annual period is 3 times smaller than at the set period or at shorter periods (Figure 8). This is in with similar altimetry-derived spectra of the Gul: region [Le Traon, 1991], where the annual cycle dc

Except for the semiannual cycle and the peaks : 70 days, most propagations are preferentially to west. Very little energy is found in southeast prc direction.

\subsection{Seasonal Variations in the Spectral Charact}

In order to examine possible seasonal variations the sea level anomalies to compute the rms varic austral summer (April 15 to October 15) (Figure 10 austral winter (October 15 to April 15) (Figure 1 


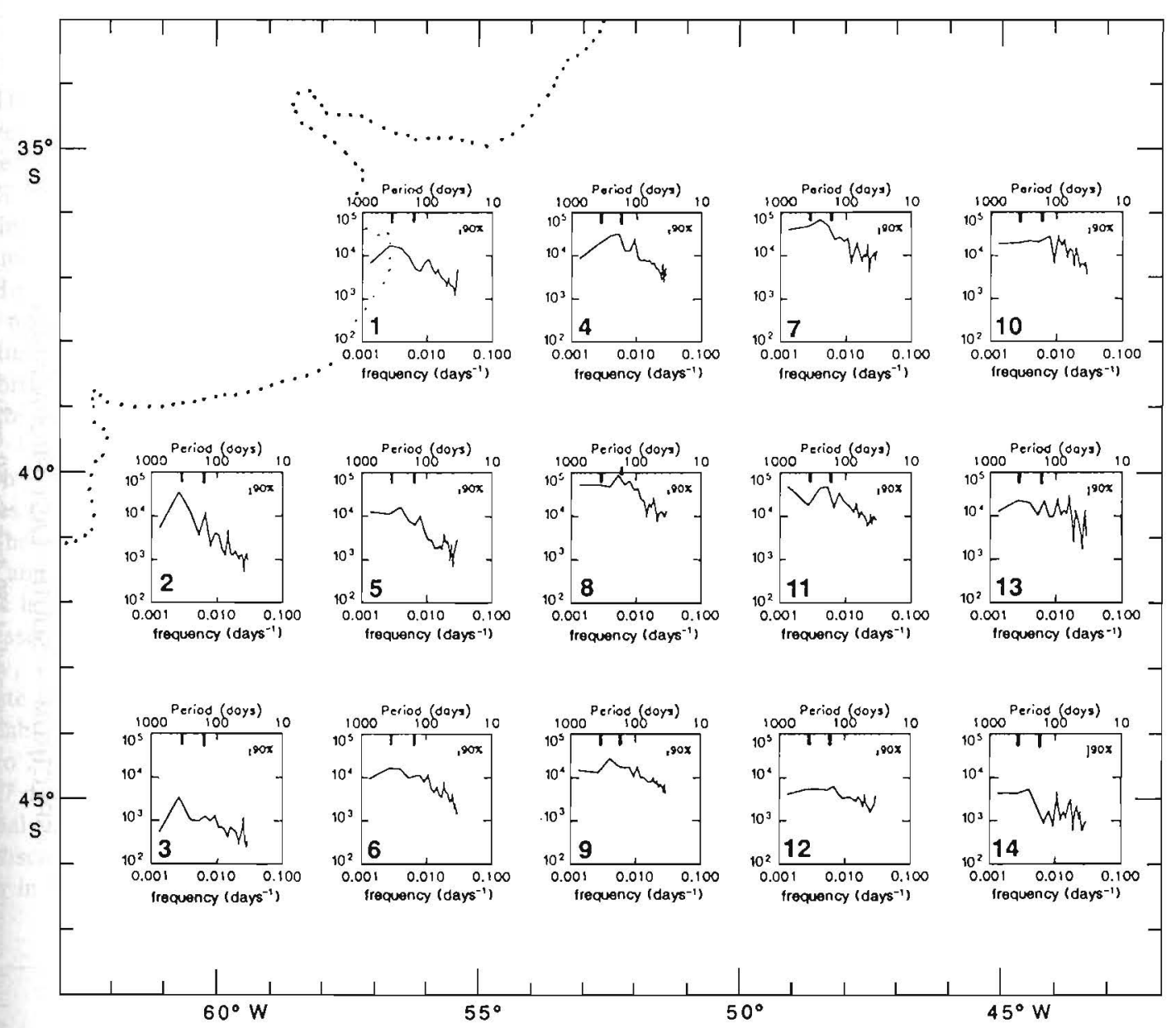

Fig. 7. Frequency spectra over $2^{\circ}$ latitude by $2^{\circ}$ longitude bins. Heavy ticks are marked for the semiannual and annual periods.

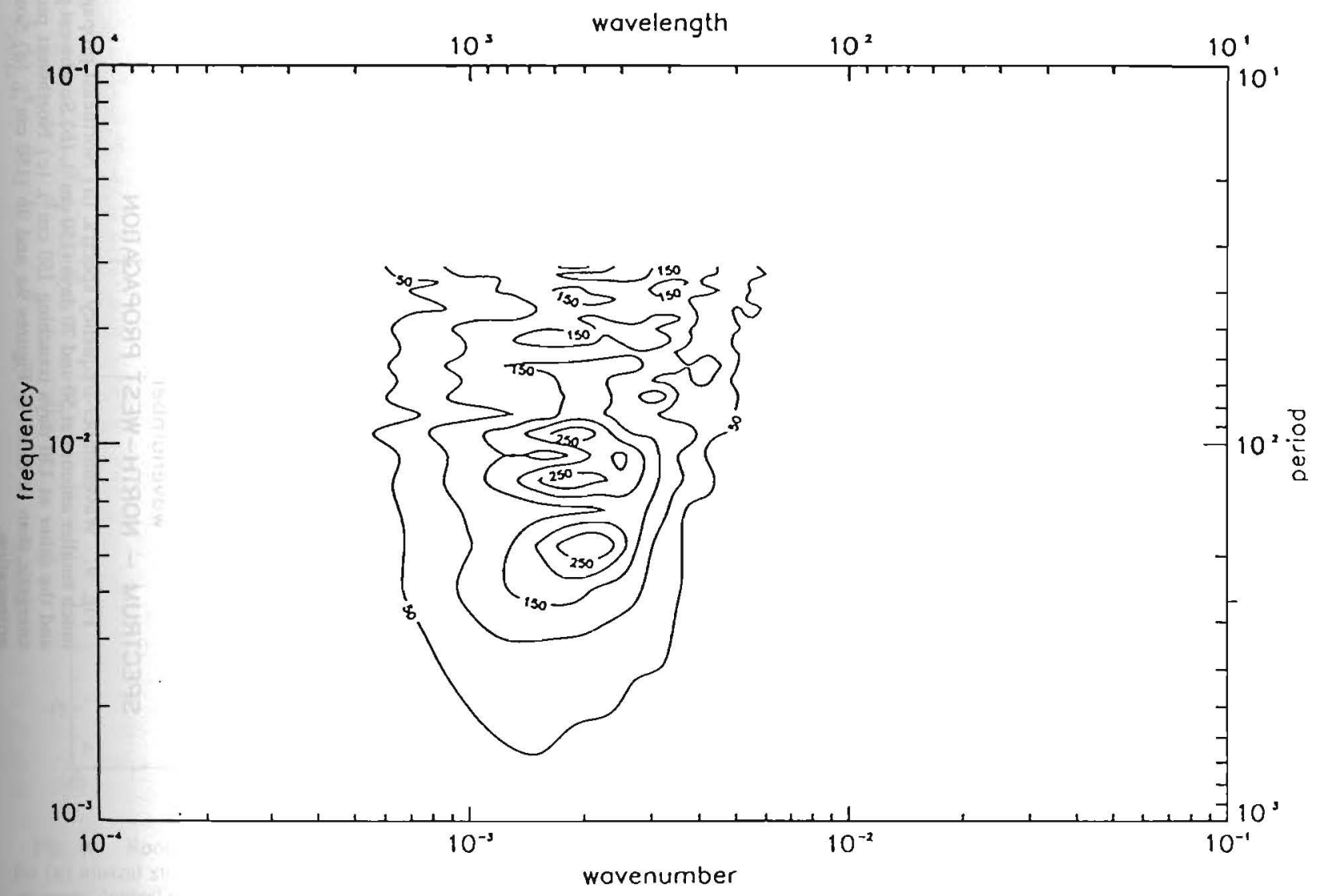

Fig. 8. Mean wavenumber-frequency spectrum for the confluence region. Values of energy higher than $200 \mathrm{~cm}^{2}$ are observed in a band limited by 300 and $800 \mathrm{~km}$ in spatial scales and by 80 and 200 days in time scales. 

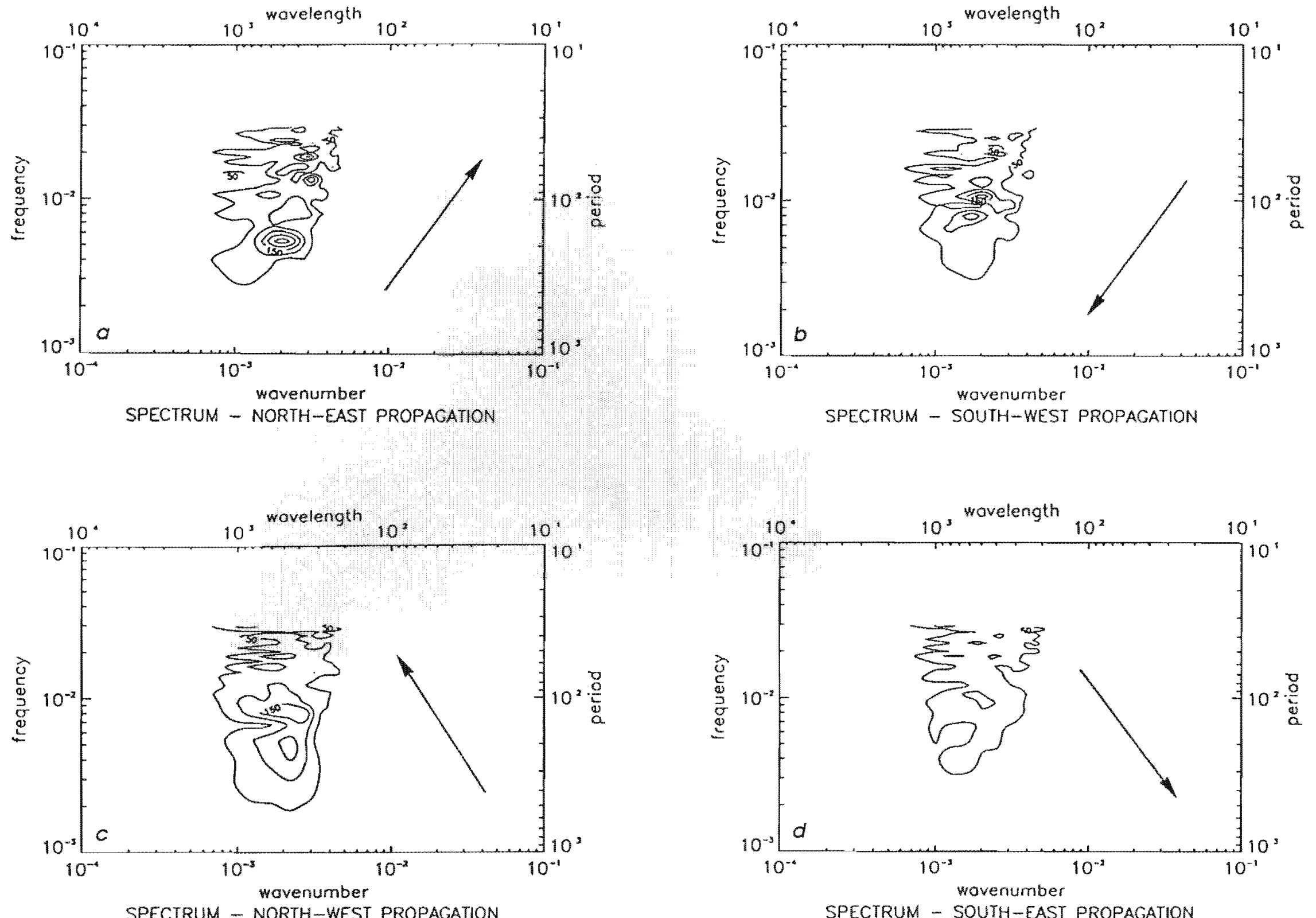

Fig. 9. Wavenumber-frequency spectra. (a) Northeast propagation. A high quantity of energy is observed at 180 days $\left(>250 \mathrm{~cm}^{2}\right)$; a much smaller amount at 50 and 70 days $\left(150 \mathrm{~cm}^{2}\right)$. (b) Southwest propagation. Two peaks are observed: one at 80 days (reaching $\left.200 \mathrm{~cm}{ }^{2}\right)$ and the other at 130 days (reaching $150 \mathrm{~cm}^{2}$ ). (c) Northwest propagation. Two peaks are observed at 130 and 180 days, although less energetic than in those in Figures $9 a$ and $9 b\left(150 \mathrm{~cm}^{2}\right) .(d)$ Southeast propagation. Very little energy is observed in that direction of propagation. 
rately. The seasonal variations are still with respect to the mean over 2 years. Seasonal variations are small but significant (the error associated with one standard deviation is less than $10 \%$ on these maps). In summer the energetic central peak is intensified: the winter maximum is $28 \mathrm{~cm}$, whereas the summer maximum reaches $32 \mathrm{~cm}$ and extends further south. However, the maxima remain at the same location. We also notice a summer intensification near the Río de La Plata estuary.

The corresponding maps of isocorrelation at 17 days show that mesoscale structures are, in general, more correlated in summer. On the other hand, it seems that the southward extension of the central region in summer corresponds to structures poorly correlated in time (isocorrelation less than $15 \%$ ). The comparison between wavenumber spectra in summer and in winter (not shown) shows that globally, the energetic level is higher in summer and that the difference occurs essentially at wavelengths larger than $300 \mathrm{~km}$.

Finally, we consider each year of data separately and recompute the variability statistics. The maximum in SLA rms variability reaches $32 \mathrm{~cm}$ the first year, whereas it is limited to $28 \mathrm{~cm}$ the second year. Although, the isocorrelation at 17 days has values between 5 and $50 \%$ in each year, the spatial variation of the isocorrelation is quite different and mesoscale structures are in general, more correlated the first year in the frontal region.
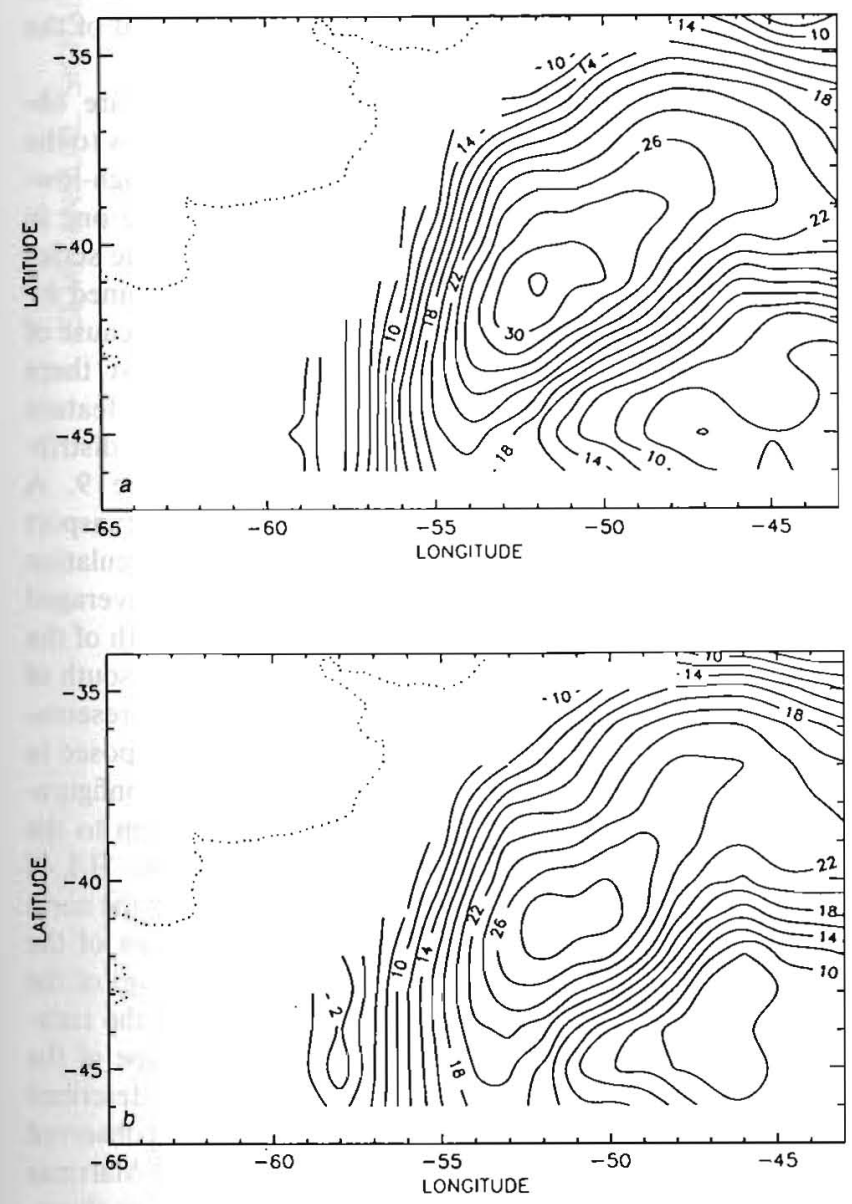

Fig. 10. Root-mean-square variability of sea surface topography for $(a)$ austral summer and $(b)$ austral winter $(2 \mathrm{~cm}$ isolines). The energetic central part is intensified in summer and extends further to the south.

\section{Discussion}

In this section we discuss the observed signals presented in section 3. We first focus on the signals with a period smaller than 150 days and then on the semiannual cycle. Finally, we discuss the total variability.

\subsection{Signals With a Period Less Than 150 Days}

The signals with periods less than 150 days are of two types: highly energetic westward propagating signals responsible for the peaks at 80 days and 130 days in Figures $8,9 b$, and $9 c$, and the less energetic eastward propagating signals associated with the peaks at 50 and 70 days. For periods between 75 and 150 days, the signal shows a significant amplitude of around $15 \mathrm{~cm}$ only in the region where the water depth is deeper than $3000 \mathrm{~m}$ (figure not shown). In this band, most of the signal has a propagation direction to the west.

The 80-day peak (propagation direction to the southwest at a wavelength of $500 \mathrm{~km}$ ) may be related to the southward extension of the Brazil Current described by Legeckis and Gordon [1982]. They report that the southern limit of this extension fluctuates within the region limited by the latitudes $38^{\circ}$ and $46^{\circ} \mathrm{S}$ and longitudes $50^{\circ}$ and $56^{\circ} \mathrm{W}$, with time periods as short as 2 months. The 80 -day peak described in section 3.5 corresponds fairly well to those scales.

One may wonder whether these westward propagating signals observed with Geosat are consistent with Rossby wave characteristics. In the presence of a mean zonal current $U$ the dispersion relation for a first baroclinic Rossby wave is given by

$$
\omega=k\left(U K^{2}-\beta\right) /\left(K^{2}+R i^{-2}\right)
$$

where $\omega$ is the angular frequency of the Rossby wave, $K$ is its wavenumber $\left(K^{2}=k^{2}+l^{2}\right), k$ and $l$ being the zonal and meridional wavenumber, respectively, $\beta$ is the meridional variation of the Coriolis parameter, and $R i$ is the first internal Rossby radius of deformation. Given a mean Rossby radius of about $27 \mathrm{~km}$ for the region [Houry et al., 1987], a $500-\mathrm{km}$-wavelength Rossby wave with a northwest (southwest) propagation should have a period of approximately 19 months in the absence of any zonal current $(U=0)$. A mean eastward zonal current $U(U>0$, like the eastward current of the Brazil-Malvinas confluence) would tend to increase further the period of the Rossby wave. Meridional variation of bottom topography also modifies the dispersion relation of baroclinic Rossby waves. In the confluence region the ocean depth increases to the south by about $1 \mathrm{~km}$ over $1000 \mathrm{~km}$, thus the topographic effect is as important as the $\beta$ effect and will induce an even smaller phase velocity. Therefore the westward propagating signals observed in the average spectrum at periods from 75 to 150 days do not correspond to baroclinic Rossby wave characteristics.

However, these signals do present characteristics that may be consistent with barotropic Rossby wave dynamics. In the absence of a mean current, a 500-km-wavelength barotropic Rossby wave with a northwest (southwest) propagation should have a period of approximately 75 days. Both the eastward mean current (a few centimeters per second when averaged over the whole water column) and the meridional bottom slope (slight shoaling to the north with a slope of about $5 \times 10^{-4}$ ) will act to decrease the phase velocity and therefore increase the period. Therefore these westward propagating 

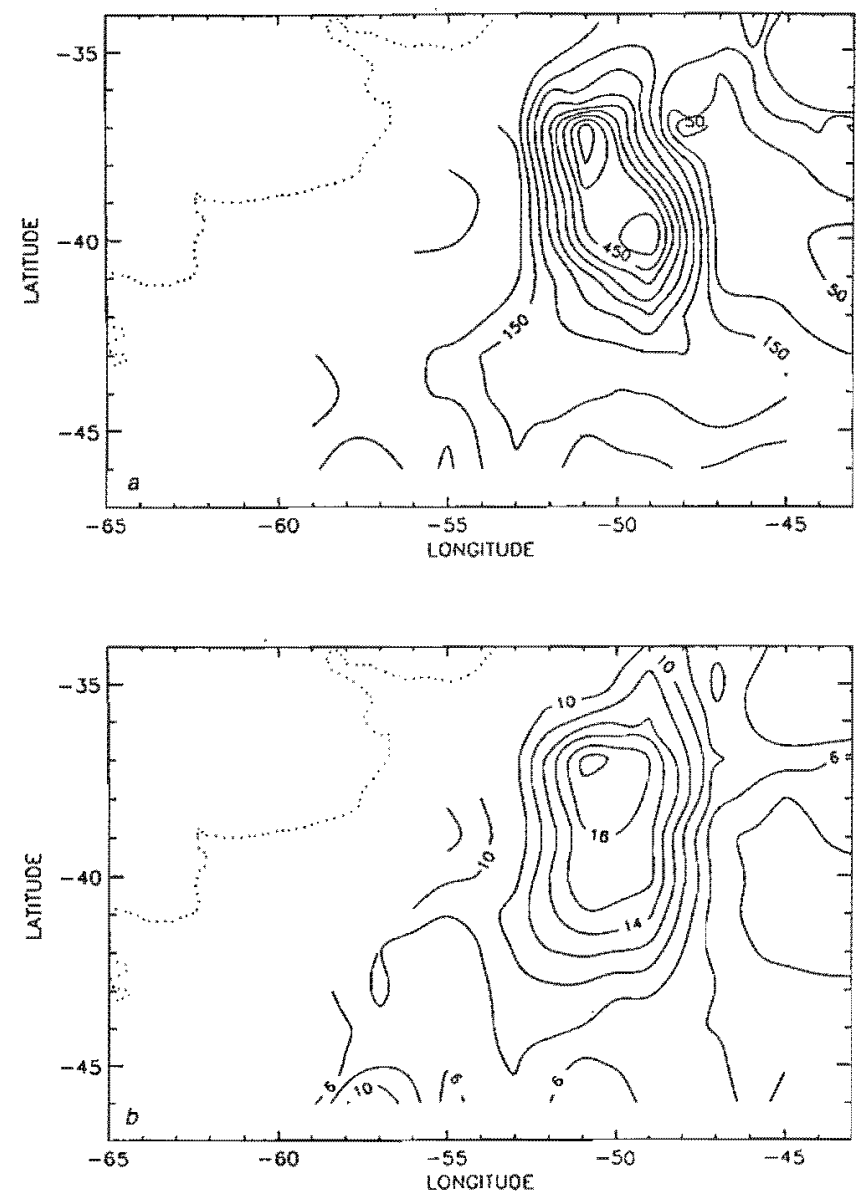

Fig. 11. (a) Relative energy of the semiannual period signal to the total energy of the variability (in percent). The semiannual component explains up to $20 \%$ of the total variance in the frontal region. (b) Relative energy of the semiannual component to the annual component (in percent). The semiannual component dominates.

signals observed with Geosat at periods between 75 and 150 days are consistent with barotropic Rossby wave dynamics.

The two peaks at 50 and 70 days which appear only in the northeast propagation may be the signature of the retreat of the Brazil Current after its extension. During its retreat, the Brazil Current sheds numerous eddies that have a diameter of around $150 \mathrm{~km}$ [Legeckis and Gordon, 1982]. The retreat may appear as a signal with a smaller wavelength and a shorter period than the southwestward pulses because of the shedding of eddies.

As we already commented in section 3.4 , there is little energy in the southeast propagation, i.e., perpendicular to the slope. Eastward propagating signals may be steered by the bottom bathymetry and have a direction of propagation to the northeast.

\subsection{The Larger-Period Signals}

The clear dominance of the semiannual component and the weakness of the annual component is a surprising result. Similar data analyses with the same 2 years of Geosat data over the Gulf Stream region show a strong annual signal and a weak semiannual signal [Le Traon, 1991]. The behavior in the Brazil-Malvinas confluence is different.

The semiannual signal explains up to $20 \%$ of the total variability in the Brazil-Malvinas confluence region, the maximum percentage being reached in the frontal region (Figure 11a). The relative energy of the semiannual component to the annual component (Figure $11 b$ ) reveals clearly that the semiannual component is larger over most of the domain (except to the east and the south in the Malvinas Current region). In the frontal region, the ratio reaches values of $500 \%$. Clearly, the semiannual signal is associated with frontal motions.

The semiannual signal has been characterized by its phase $\phi_{i}$ and amplitude $a_{i}$ at each location when performing the spectral analyses of section 3 . It is now mapped month by month over a full cycle, i.e., over 6 months (Plate 1). This is done by calculating first the mean of $a_{i} \cos \left(2 \pi t / 6+\phi_{i}\right)(t$ is the time in months) on $0.5^{\circ} \times 0.5^{\circ}$ squares and then applying an objective analysis of the resulting values. The covariance function of the objective analysis is chosen to be Gaussian with an e-folding distance of $100 \mathrm{~km}$. The semiannual signal appears as a series of large-scale positive and negative anomalies parallel to the continental slope. These anomalies are strong, with amplitudes varying between -20 and $+20 \mathrm{~cm}$, and are observed between $42^{\circ} \mathrm{S}$ and $36^{\circ} \mathrm{S}$ in latitude and $53^{\circ} \mathrm{W}$ and $48^{\circ} \mathrm{W}$ in longitude. They are aligned along the $5500-\mathrm{m}$ isobath and do not extend over water shallower than $3000 \mathrm{~m}$ nor deeper than $6000 \mathrm{~m}$. These spatial limits clearly correspond to the location of the cyclical excursions of the front at the semiannual period described by Olson et al. [1988]. The semiannual signal has a clear north-northeastward propagation with a phase speed of the order of 2.5 to $3.3 \mathrm{~cm} \mathrm{~s}^{-1}$ (i.e., 2.2 to $2.8 \mathrm{~km} \mathrm{~d}^{-1}$ ).

At one time, three successive large anomalies are observed, and two configurations are possible: either low to the south (low-high-low; L-H-L) or high to the south (high-lowhigh; H-L-H). The strongest anomaly is always the one in the center. Several possible variations can create the series of three extrema. This series of three can be obtained by changing the front's location, intensity, or shape. Because of the propagation speed observed to the north-northeast, there is necessarily some change in location. A stationary feature with only changes in intensity would appear equally distrib. uted over the four directions presented in figure 9. A schematic of the geostrophic time averaged mass transport in the upper $1000 \mathrm{~m}$ (Figure 1) shows that two recirculation cells are associated with the front. In this time-averaged picture, one recirculation cell is tight and to the north of the front, the other one appears more spread out to the south of the front in the Malvinas Current. A schematic representation of the dynamic height of the front system is proposed in Figure 12. A plausible explanation of the L-H-L configuration, is that the "high" corresponds to an extension to the south of the front (case 1 of Figure 12) whereas the H-L-H configuration may correspond to the front receding to the north (high to the north) (case 2 of Figure 12). Variations of the intensity of the front, e.g., sharpening (or weakening) of the Brazil-Malvinas front with increases (decreases) of the recirculation cells on both sides or variation of the shape of the frontal system can complicate the simplistic picture described above. However, it is clear that the semiannual signal observed with Geosat is the sea level signature of the Brazil-Malvinas frontal excursion with possible variation in intensity or shape.

What causes this semiannual signal in sea level variability? The existence of a strong second harmonic (semiannual) wave in the southern hemisphere is now well established. 

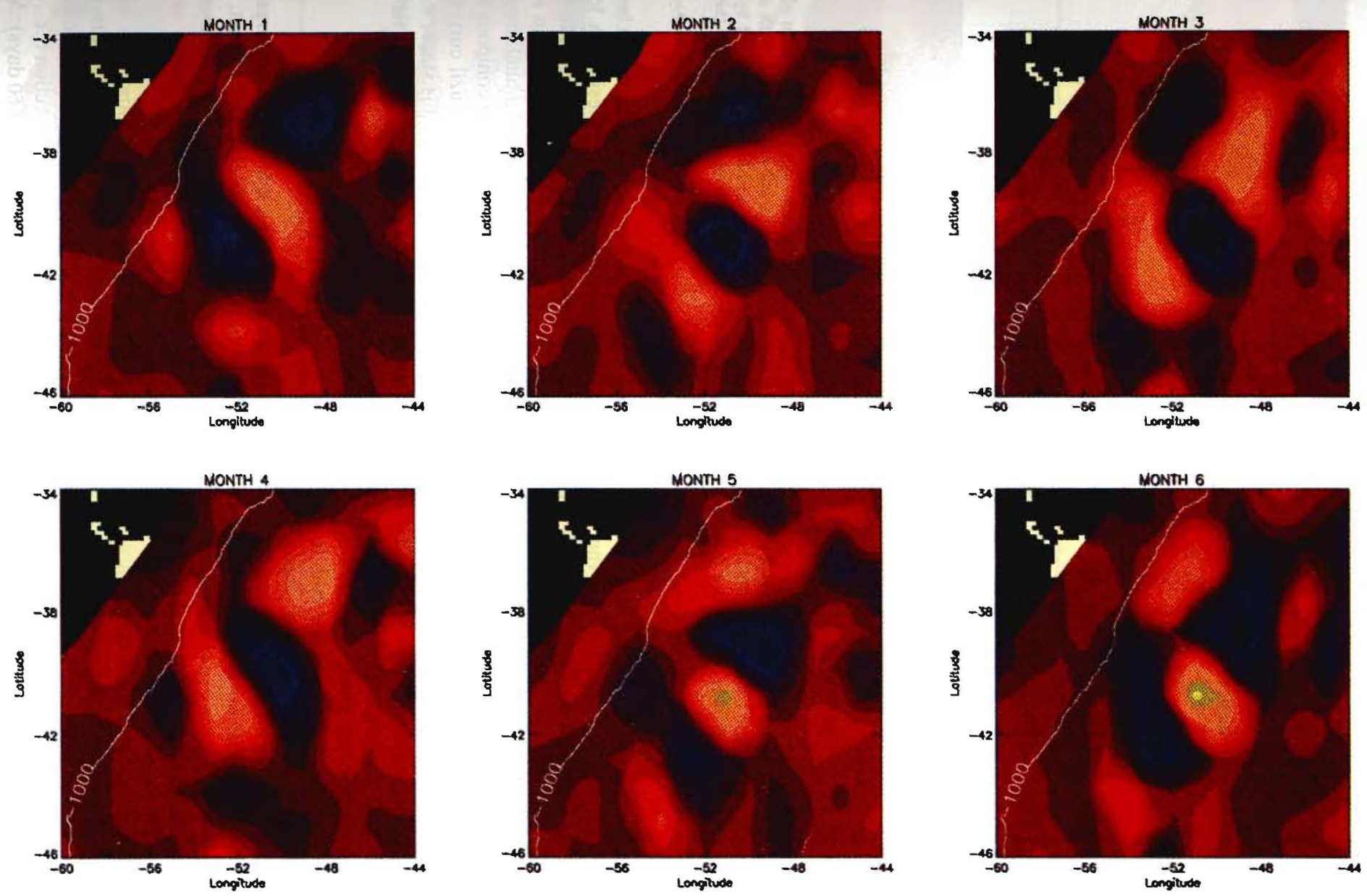

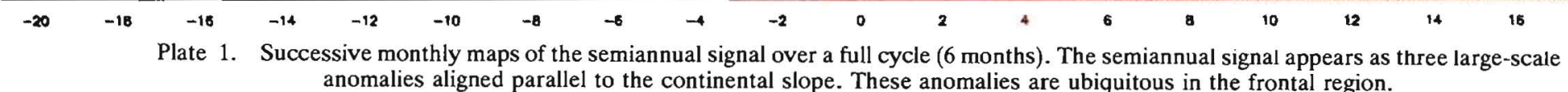


case 1

*

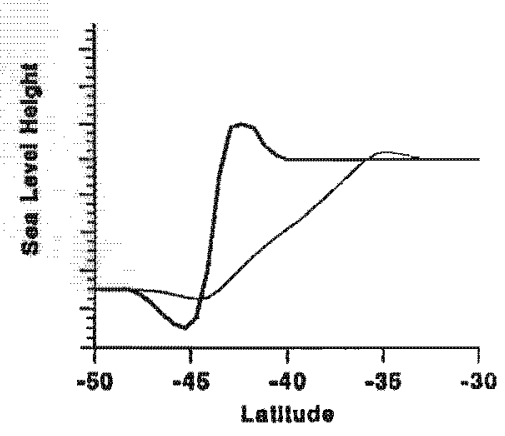

case 2

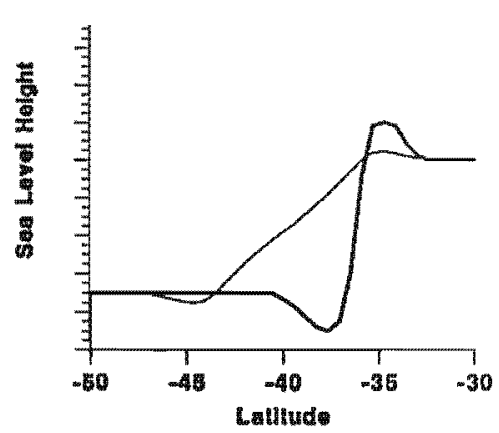

b
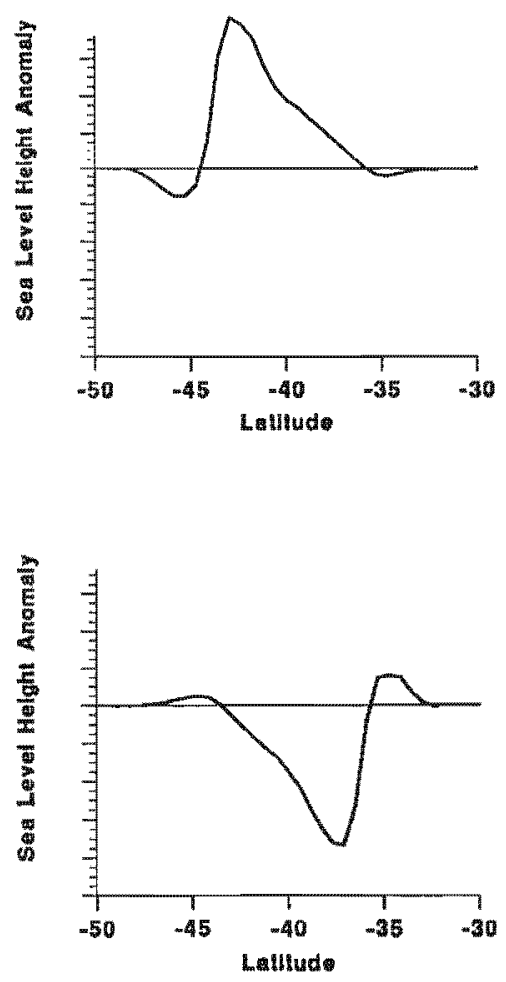

Fig. 12. Possible mterpretation of the three successive large anomalies typical of the semiannual cycle in term of variation in position of a front with a recirculation cell on each side. (a) Height profile $h$ of a schematic front with a recirculation cell on each side, taken along the subtrack labeled 420 in Figure 2 . (b) Height residual $h^{\prime}$ obtained by subtracting the mean profle (dashed line), Case 1 is a frontal excursion to the south; case 2 , a frontal excursion to the north.

This half yearly wave has been observed in various fields in the atmosphere: in the temperature [Van Loon, 1967], in the pressure Van Loon, 1966, 1972a; Hsu and Wallace, 1976], in the wind [Van Loon, 1967, 1972b, Large and Van Loon, 1989] and in the precipitation [Van Loon, 1972c]. The semiannual wave is a marked feature of the southern hemisphere atmospheric circulation and dominates the shape of the annual curve of sea level pressure (SLP), geostrophic wind and temperature gradient in the troposphere poleward of the subtropical ridge $\left(30^{\circ} \mathrm{S}\right)$. A complete explanation of this semiannual wave has not yet been given. Van Loon $[1967]$ relates it to the difference in heating in oceanic middle and continental high latitudes. The yearly and half yearly waves in pressure and zonal wind have all large interannual variations, especially at midlatitudes I Yan Loon and Rogers, $1984 a, b]$

The semiannual wave in sea level pressure (as well as the annual wave in geostrophic wind or wind stress) is secondary in the latitudes near $30^{\circ} \mathrm{S}$ over and near continents, where most of the variance is explained by the annual wave [Van Loon, 1972a, Van Loon and Rogers, 1984b]. The semiannul wave dominates over most of the middle and high southern latitudes. However, the semiannual wave in SLP at Port Stanley, Falkland Islands $\left(52^{\circ} \mathrm{S}, 58^{\circ} \mathrm{W}\right.$, just $2^{\circ}$ south of the region studied here), represents only $30 \%$ of the total variance (probably due to the presence of the South American continent) whereas it explains over $70 \%$ in other middle-latitude open ocean locations of the southern hemisphere [Van Loon and Rogers, 1984a]. Therefore according to the literature, the semiannual wave should not be strong in the confluence region, and the hypothesis of a local wind forcing at the semiannual period seems to be ruled out.

The hypothesis of a remote influence with an integrated effect of a wind forcing at the semiannual frequency is difficult to support, since the semiannual component appears to be weak in both the Malvinas and Brazil currents and to be strong only in the frontal region. At this stage, we have no explanation as to the origin of this semiannual signal in the Brazil-Malvinas frontal system.

\section{The Full Mesoscale Signal}

The semiannual cycle, which is the most energetic signal of the sea level variability as observed by Geosat, accounts for only $20 \%$ of the total variance. The full mesoscale signal is much more complex than the rather simple semiannual cycle described above.

Sea surface topography anomaly maps have been computed at 20 -day intervals using optimal interpolation in space and time. The correlation functions have been deduced from the statistical analysis of the previous section (i.e., e-folding distance of $100 \mathrm{~km}$ and $e$-folding time of 60 days). A series of 12 successive maps is shown in Plate 2, the first map corresponding to November 5,1986 . The anomaly values vary from $-0.5 \mathrm{~m}$ (black areas, associated with relatively cold water) $100.5 \mathrm{~m}$ (yellow areas, warm water).

In spite of the apparent complexity of the variability it is possible to identify several ocean processes occurring at 

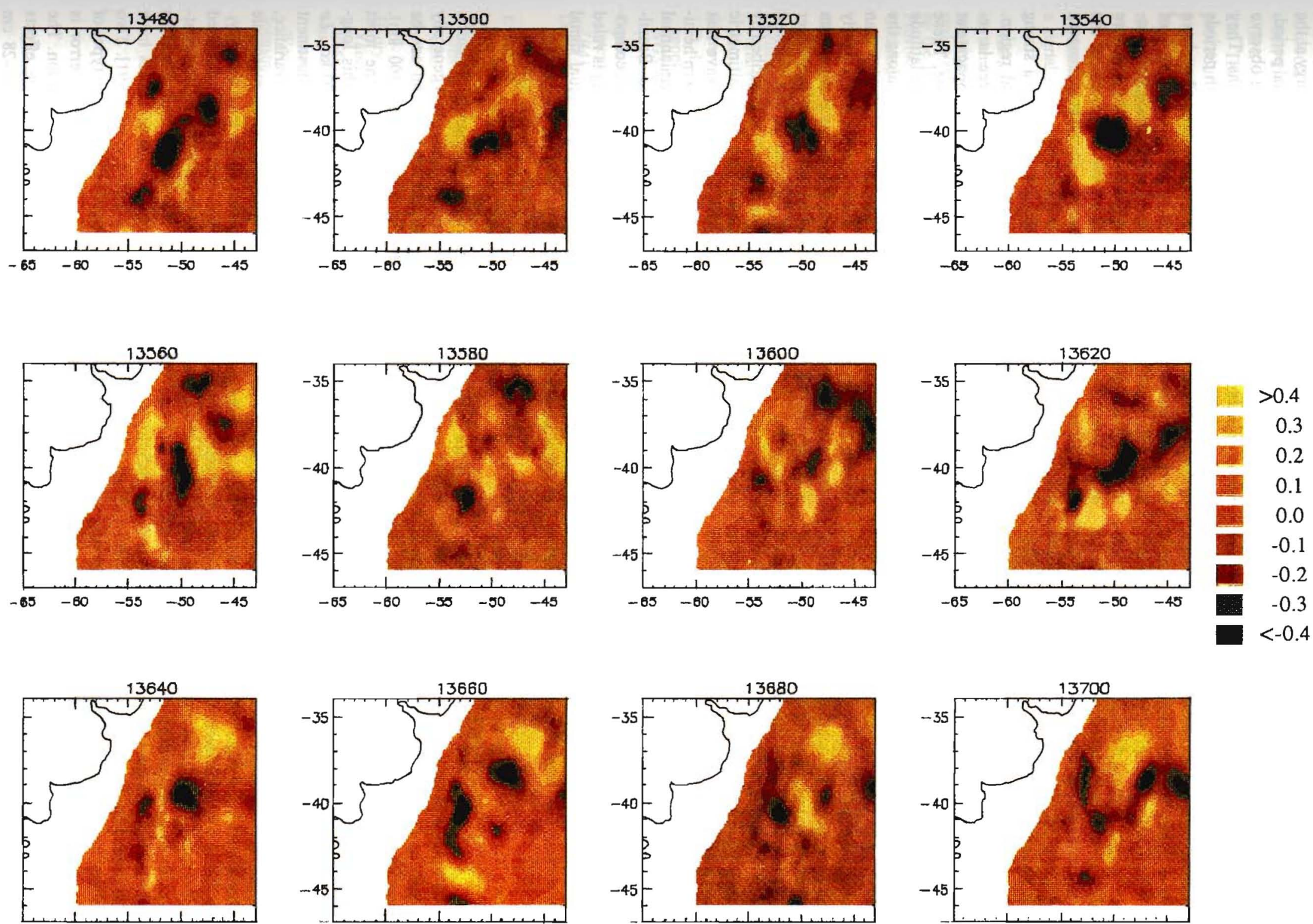

Plate 2. Successive maps of sea surface anomaly (in meters). The time interval between two maps is 20 days. The first map corresponds to November 5,1986 . The semiannual signal is easily recognized on maps corresponding to days 13520 and 13540 . It is either partially disturbed or completely masked by westward propagating anomalies (barotropic Rossby waves) on the other maps. 
given scales (in space and time). First of all, the strong anomalies are confined to the frontal region. The southeast and southwest regions of the maps remain quiet. This corroborates the variability maps presented in section 2 (Figures $3 a$ and $3 b$ ).

Two types of anomalies seem to compete on these maps: the anomalies associated with the semiannual cycle and those associated with the barotropic Rossby waves. The anomalies associated with the semiannual cycle have been depicted in Plate 1. They form an alignment of successive large-scale highs and lows parallel to the continental slope. These anomalies appear around $43^{\circ} \mathrm{S}, 53^{\circ} \mathrm{W}$, and then propagate essentially toward the northeast. The northeastward propagation of the semiannual signal, which corresponds to an advection of about 50 to $60 \mathrm{~km}$ between two successive maps, is clearly observed when the anomalies are particularly strong, for example, on days 13520,13540 , and 13560 .

The propagation of the semiannual signal is not always visible from one map to the next because of the presence of other signals such as the shorter-period ones described in section 4.1. Westward propagating signals are observed in the latitudinal band $36^{\circ}-42^{\circ} \mathrm{S}$; they enter the domain at the eastern limit $(43 \%)$ ) and then interact with the semiannual signal. For example, in the successive maps 13520,13540 , 13560 , and 13600 , anomalies associated with a wavetrain of westward propagating waves enter the domain from the east and interact with the semiannual signal observed on days 13520 and 13540 . The anomalies associated with these waves (barotropic Rossby waves; see section 4.1 ) can reach $0.4 \mathrm{~m}$ and therefore can mask partially the semiannual pattern: the large scale anomalies associated with the semiannual cycle are masked on the map corresponding to day 13600 . They reappear on the next map $(13620)$.

On the map corresponding to day 13700 a curved continuous line of lows (in black and dark red) indicate a receding of the Brazil Current to the north. Two positive anomalies (yellows) south of this line may correspond to two eddies that have been shed.

\section{Conclusion}

The scarcity of long-term time series of in situ ocean data in the southem hemisphere makes the Geosat data set obtained during the Exact Repeat Mission particularly valuable: it provides a 2-year-long time series of surface data at a fine spatial resolution over the Brazil-Malvinas confuence region.

The mesoscale activity in the Brazil-Malvinas Current confuence region, derived from altimetric data, appears anisotropic and very inhomogeneous. The anisotropy is marked with meridional variances of velocity that are typically 3 times larger than the zonal ones in the region of maximum variability. This anisotropy varies with location and can easily be related either to the meridional frontal motions (central area of the domain with bottom slope following motions) or to the more zonal motions associated with the elliptical ring formation and the permanent meander (area around $40^{\circ} \mathrm{S}, 50^{\circ} \mathrm{W}$ ). The inhomogeneity translates into low levels of sea surface variability in the Malvinas Current (less than $8 \mathrm{~cm}$, i.e., eddy kinetic energy less than $150 \mathrm{~cm}^{2} \mathrm{~s}^{-2}$ ), intermediate levels in the Brazil Current (about $16 \mathrm{~cm}$ and $800 \mathrm{~cm}^{2} \mathrm{~s}^{-2}$ ), and high levels in the frontal region $\left(30 \mathrm{~cm}\right.$ and $\left.1700 \mathrm{~cm}^{2} \mathrm{~s}^{-2}\right)$. In the Brazil-Malvinas Current confluence region, the mesoscale variations derived from altimetric data are dominated by relatively large spatial scale and low-frequency variations. The difference with similar statistics derived in the North Atlantic are striking: the spatial scales are larger in the Brazil-Malvinas confuence region, and contrary to the North Atlantic, there is very little energy at the annual period and much more energy at the semiannual period.

Beyond this dominant semiannual frequency, we observe strong signals with shorter periods of a few months. They mainly consist of westward propagating signals with periods between 75 and 150 days at scales of $500 \mathrm{~km}$. They have spectral characteristics consistent with the dynamics of barotropic Rossby waves. Their location in space and spectral characteristics lead us to interpret them as the signature of the 2-month-period fuctuations of the overshoot of the Brazil Current to the south as observed in infrared imagery by Legeckis and Gordon [1982].

The altimetric data provide clear evidence for a strong semiannual signal which is confined to the frontal region. This semiannual signal appears as a series of three largescale $(500 \mathrm{~km})$, strong $(40 \mathrm{~cm})$ anomalies which propagate at a speed of $3 \mathrm{~cm} \mathrm{~s}^{-1}$ parallel to the continental slope. These anomalies are observed between $42^{\circ} \mathrm{S}$ and $36^{\circ} \mathrm{S}$ in latitude and $53^{\circ} \mathrm{W}$ and $48^{\circ} \mathrm{W}$ in longitude. They are aligned along the $5500-\mathrm{m}$ isobath and do not extend over water shallower than $3000 \mathrm{~m}$ nor deeper than $6000 \mathrm{~m}$. These spatial limits clearly correspond to the region where the anisotropy is maximum with meridional variances of velocity that are 3 times larger than zonal variances and to the location of the cyclical excursions of the front at the semiannual period described by Olson et al. [1988]. The semiannual signal in the altimetric field is certainly associated with the semiannual wave that dominates the atmospheric circulation in the southern hemisphere. However, according to the literature, the semiannual component of the atmospheric fields over the BrazilMalvinas confluence region is second to the annual component, and therefore the hypothesis of a local forcing is ruled out. The mechanism responsible for that semiannual signal in the altimetric field has to be investigated.

\section{APPENDIX: ORBIT ERROR REMOVAL}

Of the various sources of error on altimetric measurements one of the largest is orbit error. Orbit error is generally characterized by long wavelength $(40,000 \mathrm{~km})$ and can be distinguished from the mesoscale ocean signal $(100 \mathrm{~km})$. Polynomial adjustment (degrees 0,1 , or 2 ) is the most common of the various procedures to subtract this longwavelength error for distances of the order of $1000 \mathrm{~km}$. Le Traon et al. [1991] have shown that a polynomial adjustment with weights inversely proportional to the mesoscale variance, thus taking into account the inhomogeneity of the mesoscale field, provides more accurate estimates of sea level anomaly.

Both the simple polynomial adjustment and the weighted adjustment were performed. The simple polynomial adjustment reduces the maximum of variability and increases variability on the edges of the region. These effects have been analyzed theoretically by Le Traon et al. [1991]. Two maps of SLA variability were obtained with the two types of orbit error removal (not shown). The associated error is generally of the order of $5 \%$ at one standard deviation. The two maps were similar, although we noticed the effects mentioned above (smaller value of the maximum-28 $\mathrm{cm}$ instead of $30 \mathrm{~cm}$-and increased variability along the edges for the simple polynomial adjustment). 
Let us recall that geostrophic velocity anomaly estimates (which are spatial derivatives of the SLA) are not sensitive to the precise form of the polynomial adjustment. The spatial autocorrelation function has a first zero crossing at $160 \mathrm{~km}$ when the weighted polynomial adjustment is applied, whereas with a simple polynomial adjustment, the value obtained is 125 $\mathrm{km}$. The integral scales are less sensitive to the adjustment procedure; they are 79 and $59 \mathrm{~km}$ in the case of weighted polynomial adjustment and 76 and $68 \mathrm{~km}$ after simple polynomial adjustment. The time scales (first zero crossing of the mean temporal autocorrelation function, temporal integral scales) calculated after the weighted polynomial adjustment, are greater by $5-10 \%$ than those from simple polynomial adjustment. This shows that the weighted adjustment restitutes a signal that is temporally more coherent.

Acknowledgments. We are grateful to Véronique Garçon, Sabine Arnault, and Rosemary Morrow for their useful comments while we prepared this manuscript. The comments of three anonymous reviewers have been very helpful. This work was partially supported by the PNTS (Programme National de Télédétection Spatiale) (C. Provost, CNRS) and by GREOS (Groupement de Recherches en Océanographie Spatiale) (P. Y. Le Traon, CLS Argos).

\section{REFERENCES}

Chelton, D. B., M. G. Schlax, D. L. Witter, and J. G. Richman, Geosat altimeter observations of the surface circulation of the southern ocean, J. Geophys. Res., 95, 17,877-17,903, 1990.

Cheney, R. E., J. G. Marsh, and B. D. Beckley, Global mesoscale variability from collinear tracks of Sesat altimeter data, J. Geophys. Res., 88, 4343-4354, 1983.

Cheney, R. E., B. C. Douglas, R. W. Agreen, L. Miller, D. Milbert, D. L. Porter, and N. S. Doyle, The NOAA Geosat altimeter geophysical data record user handbook, Tech. Memo. NOS NGS-46, 30 pp., Natl. Ocean. Serv., Silver Spring, Md., July 1987

Confluence Principal Investigators, CONFLUENCE 1988-1990: An intensive study of the southwestern Atlantic, Eos Trans. AGU, 7I(41), 1131-1134, 1990.

Daniault, N., and Y. Ménard, Eddy kinetic energy distribution in the southern ocean from altimetry and FGGE drifting buoys, $J$. Geophys. Res., 90, 11,877-11,899, 1985.

Evans, D. L., and S. R. Signorini, The vertical structure of the Brazil Current, Nature, 315, 48-50, 1985.

Freeland, H. J., P. B. Rhines, and T. Rossby, Statistical observations of the trajectories of neutrally buoyant floats in the North Atlantic, J. Mar. Res., 33, 383-404, 1975.

Gordon, A. L., Brazil-Malvinas confluence-1985, Deep Sea Res., 36, 359-384, 1989.

Houry, S., E. Dombrowski, P. De Mey, and J. F. Minster, BrüntVäisälä frequency and Rossby radii in the South Atlantic, J. Phys. Oceanogr., 17, 1619-1626, 1987.

Hsu, C. P. F., and J. M. Wallace, The global distribution of the annual and semi-annual cycles in sea level pressure, Mon Weather Rev., 104, 1597-1601, 1976.

Johnson, M. A., Southern ocean surface characteristics from FGGE buoys, J. Phys. Oceanogr., 19, 696-705, 1989.

Large, W. G., and H. Van Loon, Large scale, low frequency variability of the 1979 FGGE surface buoy drifts and winds over the southern hemisphere, J. Phys. Oceanogr., 19, 216-232, 1989.

Legeckis, R. L., and A. L. Gordon, Satellite observations of the
Brazil and Falkland currents-1975 to 1976 and 1978, Deep Sea Res., 29, 375-401, 1982

Le Traon, P.-Y., Time scales of mesoscale variability and their relationship with spatial scales in the North Atlantic, J. Mar. Res., 49, 467-492, 1991.

Le Traon, P.-Y., M. C. Rouquet, and C. Boissier, Spatial scales of mesoscale variability in the North Atlantic as deduced from Geosat data, J. Geophys. Res., 95, 20,267-20,285, 1990.

Le Traon, P.-Y., C. Boissier, and P. Gaspar, Analysis of errors due to polynomial adjustments of altimeter profiles, J. Atmos. Oceanic Technol., 8, 385-396, 1991.

Olson, D. B., G. P. Podesta, R. H. Evans, and O. B. Brown, Temporal variations in the separation of Brazil and Malvinas currents, Deep Sea Res., 35, 1971-1990, 1988.

Patterson, S. L., Surface circulation and kinetic energy distributions in the southern hemisphere oceans from FGGE drifting buoys, J. Phys. Oceanogr., 15, 865-884, 1985.

Piola, A. R., H. A. Figueroa, and A. A. Bianchi, Some aspects of the surface circulation south of $20^{\circ} \mathrm{S}$ revealed by the First GARP Global Experiment, J. Geophys. Res., 92, 5101-5114, 1987.

Podesta, G. P., O. B. Brown, and R. H. Evans, The annual cycle of satellite-derived sea surface temperature in the southwestern Allantic Ocean, J. Clim., 4, 457-467, 1991.

Provost, C., V. Garçon, and S. Garzoli, Sea level variability in the Brazil and Malvinas confluence region, Adv. Space Res., 9, 7387-7392, 1989

Provost, C., O. Garcia, and V. Garçon, Analysis of satellite SST time series in the Brazil-Malvinas Current confluence region: Dominance of the annual and semi-annual periods, J. Geophys. Res., 87, 17,841-17,858, 1992.

Van Loon, H., On the annual temperature range over the southern oceans, Geogr. Rev., 56, 497-515, 1966.

Van Loon, H., The half-yearly oscillations in middle and high southern latitudes and the coreless winter, J. Atmos. Sci., 24, 472-486, 1967.

Van Loon, H., Pressure in the southern hemisphere, in Meteorology of the Southern Hemisphere, Meteorol. Monogr. 35, edited by C. W. Newton, pp. 59-86, American Meteorological Society, Boston, Mass., $1972 a$.

Van Loon, H., Wind in the southern hemisphere, in Meteorology of the Southern Hemisphere, Meteorol. Monogr. 35, edited by C. W. Newton, pp. 87-99, American Meteorological Society, Boston, Mass., $1972 b$.

Van Loon, H., Cloudiness and precipitation in the southern hemisphere, in Meteorology of the Southern Hemisphere, Meteorol. Monogr. 35, edited by C. W. Newton, pp. 101-111, American Meteorological Society, Boston, Mass., $1972 c$.

Van Loon, H., and J. C. Rogers, Interannual variations in the half yearly cycle of pressure gradients and zonal wind at sea level on the southern hemisphere, Tellus, Ser. A, 36, 76-86, $1984 a$.

Van Loon, H., and J. C. Rogers, The yearly wave in pressure and zonal geostrophic wind at sea level on the southern hemisphere and its interannual variability, Tellus, Ser. A, 36, 348-354, $1984 b$.

Zlotnicki, V. L., L.-L. Fu, and W. Patzert, Seasonal variability in global sea level observed with Geosat altimetry, J. Geophys. Res., 94, 17,959-17,969, 1989.

P.-Y. Le Traon, CLS Argos, 18 avenue G. Coriolis, F-31055 Toulouse Cedex, France.

C. Provost, LODYC, Universite de Paris V1, Tour 14 2E, 4 place Jussieu, 75235 Paris Cedex 05, France.

(Received December 21, 1992; revised March 16, 1993; accepted March 16, 1993.) 